\title{
Idiopathic Ketotic Hypoglycemia
}

National Cancer Institute

\section{Source}

National Cancer Institute. Idiopathic Ketotic Hypoglycemia. NCI Thesaurus. Code C131855.

Ketotic hypoglycemia that usually occurs in young, thin children in association with infection or fasting, and which typically resolves by age 6-8 years. 